\title{
The Effects of Pre-task, On-line, and both Pre-task and On-line Planning on Fluency, Complexity, and Accuracy - The Case of Iranian EFL Learners' Written Production
}

\author{
Faramarz Piri (Corresponding author) \\ University of Isfahan, Iran \\ E-mail: Faramarz.ps@gmail.com
}

Hossein Barati

University of Isfahan, Iran

Saeed Ketabi

University of Isfahan, Iran

Received: January 1, 2012

Accepted: April 9, 2012

Published: June 1, 2012

doi:10.5539/elt.v5n6p158

URL: http://dx.doi.org/10.5539/elt.v5n6p158

\begin{abstract}
Previous studies on the effect of planning on language production have revealed that planning does have a positive effect on language performance in terms of fluency, complexity, and accuracy. The present study was an attempt to investigate the effects of pre-task, on-line, and both pre-task and on-line planning on fluency, accuracy, and complexity of Iranian EFL learners' written production. Forty five Iranian learners of English performed a narrative task based on a series of six pictures. The narratives, then, were coded to measure the fluency, accuracy, and complexity of the participants' production. The results of one-way ANOVA revealed that on-line planning (OLP) and pre-task plus on-line planning (PTP+OLP) had no effect on the fluency, complexity, and accuracy of the Iranian EFL learners' written narratives. However, pre-task planning (PTP) had a significant effect on one variable of fluency (i.e. syllables per minute) but it had no effect on the complexity and accuracy of the written narratives. Findings have pedagogical implications for language teachers and syllabus designers in EFL context.
\end{abstract}

Keywords: Accuracy, Complexity, Fluency, Pre-task planning, On-line planning, Pre-task plus on-line planning

\section{Introduction}

How planning affects second language production is of both theoretical importance to second language acquisition (SLA) researchers and of practical importance to language teachers (Ellis, 2005). Planning is considered to be a strategy that frees learners from real time communicative stress (Sangarun, 2001), frees up learners' attentional resources to attend to form (Van Patten, 1990, 1996), and allows learners to process the content and language of their planned production at a deeper and more meaningful level (Wendel, 1997).

Empirically, previous studies on the effects of both pre-task and on-line planning on written production have indicated that planning has a positive effect on language performance in terms of fluency, complexity, and accuracy in general (Skehan, 1996; Wendel, 1997; Skehan \& Foster, 1999; Yuan, 2001; Sangarun, 2001; Yuan \& Ellis, 2003; Ellis \&Yuan, 2004). Some studies suggest that accuracy is raised when pre-task planning is allowed (Ellis, 1987; Mehnert, 1998; Kawauchi, 2005), but others do not support this claim (Wendel, 1997; Yuan, 2001; Yuan \& Ellis, 2003; Ellis \&Yuan, 2004; Kawauchi, 2005), instead, they support the influence of planning on complexity and fluency. On the other hand, the overall generalization of the effects of on-line planning on language production is that it promotes the accuracy of learners' production as learners are given time to plan on-line and to monitor their output, although other studies give support to the positive effect of complexity and fluency (Yuan, 2001; Yuan \& Ellis, 2003, Ahmadian \& Tavakoli, 2011) on on-line planning, too. In general, mixed results have been found regarding the impact of planning on language production. Therefore, it seems studies on the effects of planning on second language production would further our understanding of the cognitive processes involved in second language (L2) production. 
Further, the overwhelming majority of studies arriving at these findings have investigated the effects of both types of planning on oral tasks. A few studies (Yuan, 2001; Ellis \& Yuan, 2004; Rahimpour \& Nariman-Jahan, 2011), however, have investigated the effects of planning on written tasks. Furthermore, in the Iranian context, planning has not been much investigated on the written production, and it is not clear to what extent planning affects written language production of Iranian EFL learners and what language aspects - if any - are most influenced by planning. Moreover, the effects of different planning conditions (i.e. pre-task planning, on-line planning, and both pre-task and on-line planning) on written performance have not been much investigated in research in this context.

With regard to the planning time, however, previous studies (e.g. Crookes, 1989; Foster and Skehan, 1996; Wendel; 1997; Ellis \& Yuan, 2004) examining the effects of pre-task planning on language production have mostly allowed 10-minute planning time prior to performing the main task. Mehnert (1998) found that when 10-minute planning time was provided the effects of planning on the three aspects of language-fluency, accuracy, and complexity could be measured for oral production. However, in the present study 5-minute planning time was provided to the participants prior to performing the main task. The choice of five-minute planning time was based on the pilot study that was conducted with a similar number of participants before the main task.

Furthermore, whether the use of both pre-task and on-line planning on written language has any effect on language production is an area which has not been investigated so far. The present study is, thus, an attempt to investigate the effects of pre-task, on-line, and both pre-task and on-line planning on fluency, complexity, and accuracy of the Iranian EFL learners' written narratives.

\section{Planning}

Planning is the independent variable of the study which was investigated in the present paper. Planning, as one of several processes involved in the written production, has been considered an important process in SLA, therefore the role that planning plays in writing should be taken into account in relation to the other composing processes such as monitoring, revising, and evaluating. Ellis (2005) distinguished between two principal types of task planning; pre-task planning that takes place before performing the task, and on-line planning which refers to planning that takes place while performing the task. Pre-task planning is further divided into rehearsal and strategic planning. In rehearsal, learners are given the opportunity to "perform the task before the main performance" (Ellis, 2005, p.3). On the other hand, in strategic planning learners prepare the content of the task before performing the main task. On-line planning is also divided into pressured and unpressured planning. In pressured planning learners are not provided with enough time to plan on-line, while in unpressured planning they are given enough time to plan (see Figure 1).

Studies examining the effect of pre-task planning and on-line planning on written production (e.g. Ellis and Yuan, 2004) revealed that pre-task planning resulted in more fluent and complex written performance while, on-line planning assisted accuracy of the written production. However, Yuan (2001) found no impact for on-line planning on written language production.

\section{Complexity, Accuracy and Fluency}

A general goal for many language learners is to achieve native-like ability in language. This is concerned with improving three main areas or dimensions of performance which are distinguished as: fluency, complexity, and accuracy (Skehan, 1996 and 1998). These three dimensions have been the essence of investigating the effects of planning on language production in various studies. The focus of complexity and accuracy is on form whereas fluency is concerned with the primacy of meaning (Foster \& Skehan, 1996). Skehan (1996, p. 46) identifies accuracy as concerned with 'a learner's capacity to handle whatever level of interlanguage complexity she has currently attained'. He also states that complexity relates to 'the stage and elaboration of the underlying interlanguage system' (p. 46).

According to Ellis and Barkhuizen (2005), 'elaborated language' could be taken into consideration from two different senses: First, cutting edge development of the learner language, which is not yet completely automatic, and second, learners' preparedness to make use of an extensive range of linguistic structures. Fluency, as Skehan (1996) argues, 'concerns the learner's capacity to mobilize an interlanguage system to communicate meaning in real time' (p. 46), and when learners are producing more fluent language, Ellis \& Barkhuizen (2005), argue they are prioritizing meaning over form.

One of the issues regarding complexity, accuracy, and fluency which has been hotly debated is that of the trade-off effects among them. Skehan (1996) argued that these three areas enter the competition with one another for attentional resources. He further proposed that because learners have limited processing capacity, they will need to prioritize and that it leads them to focus on one aspect of performance at the expense of others. He argues that 
trade-off appears to affect complexity and accuracy. That is, if learners choose to take risks, accuracy will suffer. However, if they concentrate on controlling their resources to ensure accuracy, then complexity suffers. On the other hand, Wendel (1997) has proposed that the trade-off involves fluency and accuracy. This is in line with Yuan and Ellis's (2003) findings. This can be explained in the sense that why some studies found that pre-task planning aided complexity but not accuracy and other studies vice versa.

\section{The Study}

The present research aimed to investigate the effects of pre-task, on-line, and both pre-task and on-line planning on EFL learner's written performance. The following research questions addressed here were:

\subsection{Research Questions}

1. Does pre-task planning significantly affect the fluency, complexity, and accuracy of the Iranian EFL learners' written narratives?

2. Does on-line planning significantly affect the fluency, complexity, and accuracy of the Iranian EFL learners' written narratives?

3. Does the use of both pre-task and on-line planning significantly affect the fluency, complexity, and accuracy of the Iranian EFL learners' written narratives?

Based on the research questions postulated above, the following null hypotheses were formulated:

\subsection{Research Hypotheses}

1. Pre-task planning will have no significant effect on the fluency, complexity, and accuracy of the Iranian EFL learner's written performance.

2. On-line planning will have no significant effect on the fluency, complexity, and accuracy of the Iranian EFL learner's written performance.

3. The use of both pre-task and on-line planning will have no significant effect on the fluency, complexity, and accuracy of the Iranian EFL learner's written performance.

\subsection{Participants}

The participants of the study were 45 EFL learners (10 males and 35 females) studying English translation and English literature at the university of Isfahan, Iran. They were between the ages of 20 and 27 years. They were selected from among the senior students and had passed their writing course in English prior to conducting the study. They were from Persian language background. Also, to ensure that the participants' English language experience are equal, they were required to fill in a questionnaire about the number of terms they had passed at university, the score of their writing course, and their total average score. It was supposed that they would provide us with reliable information regarding their educational background. The data obtained from the questionnaires showed that there were no significant differences between participants in terms of the number of terms they had passed at university, the score of their writing course, and their total average score.

\subsection{Tasks}

\subsubsection{Written Narrative Task}

The task for the participants to complete was a narrative writing task based on a series of six pictures (adopted from Heaton 1975). The pictures were in black and white (see Appendix A) but were quite clear to be understood by the participants. The pictures were designed to indicate a story in chronological order of events, it, therefore, required interpretation on the part of the participants.

Previous research on oral and written narrative tasks (e.g. Skehan \& Foster, 1999; and Ellis \& Yuan, 2004) indicated that such tasks would stretch the learners' linguistic resources provided they require learners' interpretation. The same task has been used in a number of previous studies on written narratives (Ellis, 1987; Yuan, 2001; and Ellis \& Yuan, 2004). Therefore, the assumption underlying using the same task in the present study was that it would presumably permit the comparison of the results of this study with those in the literature in a more reliable way.

\subsubsection{Questionnaire}

Adopting previous research methodology (see Yuan 2001, Yuan and Ellis 2003, and Ellis and Yuan 2004), the researcher decided to design a questionnaire in the participants' first language, Persian, to investigate how the participants used the planning time available to them. The data collected by the questionnaires were to help interpret the results of the study. 


\subsection{Procedures}

In this study, planning was operationalized at three levels: pre-task planning (PTP), on-line planning (OLP), and pre-task planning plus on-line planning ( $\mathrm{PTP}+\mathrm{OLP})$. The participants performed the task in their normal classroom setting.

In the PTP condition, participants were required to write the story within 15 minutes and to produce at least 200 words. In this way, the participants were pressured to perform the task with limited chances for on-line planning. A pilot study with similar number of participants had been carried out to determine the time to be permitted to write the story. In the pilot study, there was no time limit, and the participants' different times were noted. The results of the pilot study indicated that the fastest writer completed the story in 15 minutes, whereas the slowest took 20 minutes to finish the task. The 15-minute time was selected for writing the main task in order to avoid extensive on-line planning on the part of the participants.

The participants were given a sheet of paper to write notes but were told not to write out the complete story. The notes were taken away before they started writing the task. According to Ellis \& Yuan (2004, p. 70), "removing the notes ensured that the language elicited by all the tasks was produced within the specified time limit".

As for the OLP condition, the participants were told they could take as much time as needed to write down the story and the researcher ensured that they began writing immediately. The researcher noted the time the participants spent on the task to check that this was actually longer than the time taken by the other two groups. Unlike the other two groups, however, the participants were not required to write a minimum of 200 words, "as this may have been interpreted as requiring them to write quickly" Ellis \& Yuan (2004, p. 70 ). Therefore, the participants in this condition were given no time for pre-task planning but ample time for on-line planning.

In the case of the PTP + OLP condition, as in OLP condition, the participants were given unlimited time to finish the task and were not asked to write at least 200 words. However, they were given 5 minutes time to plan their narratives prior to performing the main task.

For all three planning groups, the task instructions were given in Persian (see Appendix B) to avoid misunderstanding on the part of the participants. Also, no detailed guidance was provided to the participants in the planning groups, but they were told to plan their narratives in terms of content, organization, and language. This followed the studies of Crookes, 1996; Skehan and Foster, 1997; Wendel, 1997; Yuan \& Ellis, 2003 and Ellis \& Yuan, 2004. The task conditions are summarized in Table 1.

\subsection{Measures}

Following Ellis \& Yuan (2004), the following measures were adopted in order to evaluate the participants' written narratives in terms of fluency, complexity, and accuracy.

\subsubsection{Fluency Measures}

1. Syllables per minute: the total number of syllables produced was divided by the total number of minutes a participant took to complete the task.

2. Number of dysfluencies: the total number of words a participant reformulated (i.e., crossed out and changed) was divided by the total number of words produced.

\subsubsection{Complexity Measures}

1. Syntactic complexity: the ratio of clauses to T-units in the participants' production was calculated. T-units rather than c-units were used because the task performance was monologic and contained few elided utterances.

2. Syntactic variety: the total number of different grammatical verb forms used in the task was computed. Grammatical verb forms included tense (e.g., simple past, past continuous), modality (e.g., should, have to0, and voice (e.g., passive voice in the past).

3. Mean Segmental Type-Token Ratio (MSTTR). The participants' narratives were divided into segments of 40 words. Then, the type-token ratio of each segment was calculated by dividing the total number of different words (i.e. verbs, nouns, adjectives, and adverbs) by the total number of words produced in the segment. The MSTTR (Malvern \& Richards, 2002) was computed for each participant by adding the mean scores for his or her segments and dividing the total by the total number of segments in the narrative. This procedure was followed to take account of the effect of text length on the type-token ratio.

\subsubsection{Accuracy Measures}

1. Error-free clauses: the percentage of clauses that did not contain any errors was computed. All errors in syntax, morphology, and lexical choice were considered. Errors in lexical form or collocation were regarded as lexical errors 
(e.g., *I was waiting you).

2. Correct verb forms: the percentage of accurately used verbs in terms of tense, aspect, modality, and subject-verb agreement was calculated.

\section{Results}

\subsection{Dependant Variables}

All writings produced under the abovementioned conditions were segmented, coded, and scored based on the measures discussed above for assessing fluency, complexity, and accuracy. To determine the reliability of these measures, a second researcher segmented, coded and scored $30 \%$ of the data. Intercoder reliability coefficient magnitude was .90 for dysfluencies, .91 for clauses, .94 for T-units, .96 for accuracy scores. A series of one-way ANOVAs followed by Post-hoc Scheffé test where appropriate were then performed to test the hypotheses of the study.

As indicated in Table 2, the mean score for pre-task planning group was higher than those of the on-line planning and pre-task plus on-line planning groups. The one-way ANOVA results revealed significant differences across groups in terms of syllables per minute $(p=.04)$. However, the results of Post-hoc Scheffé test indicated that only the difference between PTP and OLP reached statistical significance with PTP outscoring OLP.

For dysfluencies, no statistically significant differences were found across groups. However, as it is shown in table 3 , the mean scores show that the pre-task planning group had less dysfluent language (i.e. they tended to cross, reformulate, and repeat less) in their written narratives than learners in on-line and pre-task plus on-line planning groups.

As for complexity, the descriptive statistics presented in Table 3 showed very similar mean scores for all complexity variables. The one-way ANOVA results revealed that there were no significant differences across the three planning groups with regard to any of the complexity variables. This indicated that none of the planning conditions (i.e. pre-task planning, on-line planning, and pre-task plus on-line planning) seem to have any effect on the learners' language structure elaboration, variety of grammatical structures, and lexical richness measured by MSTTR.

With regard to accuracy, the descriptive statistics indicated in Table 4 revealed that the mean scores for the three planning groups were close to each other for both error-free clauses and correct verbs, and this is indicated in the one-way ANOVA results which showed no statistically significant differences across the three groups for both accuracy variables.

\subsection{Questionnaires}

Immediately after the participants completed the narrative task, they were asked to complete a questionnaire which was constructed in their native language, Persian. The questionnaire asked the participants how they used the planning time available to them during completing the task and what they were concentrating on while writing their narratives. Following Ellis and Yuan (2004), the data were analyzed by counting the number of the participants in each group who referred to each of six aspects of the narrative task: (a) understanding the pictures, (b) planning the organization of the story, (c) content planning, (d) language planning, (e) use of L1, and (f) use of note. The results were presented as percentages.

As indicated in Table 6, for the aspects of the language the participants in the pre-task planning group concentrated on, $\% 47$ of the participants mentioned that they focused on language (i.e. grammar and lexis) in the process of writing. However, $\% 53$ reported they did not concentrate on language. About $\% 93$ reported that they focused on content and rhetorical planning (e.g., outlining the key events and establishing links between each picture) of the written narratives. Further, \%12 percent commented they made use of their notes in the process of writing and it was useful to them. All of the participants reported they had no problem comprehending the pictures. Only \%20 mentioned they made use of L1 during writing. These data indicate that, since most of the participants in this group concentrated on planning the content, they tended to attend to meaning at the expense of form during writing their narratives, which is manifested in their tendency towards a more fluent language.

The data obtained from the questionnaires administered to on-line planning group presented in Table 5 revealed that $\% 87$ of the participants focused on planning the language while writing. Also, $\% 93$ in the group mentioned that they concentrated on content. None of the participants mentioned having difficulty comprehending the pictures. Moreover, \%87 reported they focused on the rhetorical planning of the written narratives. Further, \%47 of the participants mentioned they made use of L1 during writing. These data indicated that the participants in this group divided their attention to both aspects of the language (i.e. form and meaning). The questionnaire data indicated in Table 6 collected from pre-task plus on-line planning group revealed similar results to those of on-line planning 
group.

\section{Discussion}

The first research question addressed the effect of pre-task planning on fluency, complexity, and accuracy in written narratives. The results of the study indicated that pre-task planning impacted the fluency (i.e. syllables per minute) of the EFL learner's written production significantly; however, it did not have significant effect on the complexity and accuracy of the written performance. The findings of this study are partially in line with the findings of the studies (Wendel, 1997; Ortega, 1999; Yuan, 2001; Yuan and Ellis, 2003; and Ellis and Yuan; 2004) which revealed that the opportunity for pre-task planning results in significantly more fluent and complex language. In addition the findings are in total agreement with Rahimpour \& Safarie (2011). They found that pre-task planning had a significant effect on fluency, but no effect on complexity and accuracy. As Ellis and Yuan, 2004 argued, the greater fluency in the case of PTP group is because pre-task planning makes content and organization planning easier. It may also help increase L2 writers' confidence to write clearly and effectively possibly reducing their need to get involved in extensive monitoring. This was indicated in the participants' answers to post-task questionnaire in which \%93 reported that they focused on content and rhetorical planning. Furthermore, Ortega (1999) argues, when the task is not challenging the learners may not find pre-task planning of much value. Thus, it can be surmised that Iranian EFL learners did not find the task challenging and therefore pre-task planning was not so much helpful to them in producing a complex text. Another possibility is that Iranian EFL learners were not familiar with planning strategies which in turn resulted in no improvement in their writing in terms of complexity.

Pre-task planning group also had less dysfluent language compared to the other planning groups but it was not statistically significant. Zimmerman (2000) found that writers have more revisions when they write in their L2 than in their L1; thus, one of the effects of allowing time for pre-task planning may be to reduce the number of revisions undertaken in L2 writing, resulting in more resemblance to L1 writing.

The second research question addressed the effect of on-line planning on fluency, complexity, and accuracy in written narratives. The findings of the studies (Yuan and Ellis, 2003; Ellis and Yuan, 2004; Ellis and Yuan, 2005) revealed that on-line planning impacted the accuracy and complexity of the written performance positively. On the other hand, Yuan, 2001 and Rahimpour \& Safarie, 2011 found no effect for on-line planning on accuracy and complexity. However, the results of the present study are in line with the findings of Yuan, 2001 and Rahimpour \& Safarie, 2011. As indicated in the post-task questionnaires, the results indicated that participants concentrated on content (Sangarun, 2005) which resulted in no improvement in accuracy. Further, Ahmadian (2011) found that guided on-line planning had positive effect on the accuracy of the learners' oral performance. Thus, the result of this study in terms of accuracy can be attributed to lack of guided planning (Mochizuki \& Ortega, 2008). Another possibility might be because of the emphasis in Iranian context on formal grammar teaching (Rahimpour and Nariman, 2010). Moreover, Yuan (2001) argues that the effect of on-line planning in the written task is not as obvious as in the oral task because the demand of doing a written task is not as great as that of an oral task. Because of the nature of writing, he postulates, learners have more time to attend to both complexity and accuracy. Further, Foster and Skehan (1996) assume that there need not always be a trade off effect between complexity and accuracy; rather learners may make an attempt to balance the demands of both.

The third research question asked whether the use of both pre-task and on-line planning has any significant effect on the fluency, complexity, and accuracy of the written narratives. The findings of the study confirmed the hypothesis of the study. That is the use of both pre-task and on-line planning had no impact on the fluency, complexity, and accuracy of the written narratives. A possible explanation is that because learners had the opportunity for both types of planning they divided their attention to both aspects of the writing task (i.e. content and form), manifested in their answers to the post-task questionnaires, which consequently resulted in no improvement in the fluency, complexity, and accuracy of the written narratives. Further, the data obtained from the questionnaires revealed that $93 \%$ of the participants reported they made use of their notes during the writing process but it did not enhance the fluency, complexity, and accuracy of their writing. This may be because Iranian EFL learners either lack the knowledge of proper planning strategies or implementing the planning strategies, as applied by skilled write in their written texts. Also, $53 \%$ of the participants mentioned they used the knowledge of L1 in composing their writing. This may also be a factor in interfering with L2 writing.

To sum up, it seems that planning has a positive effect on the fluency of the Iranian EFL learners, but it does not assist them in terms of complexity and accuracy. This may be the result of the emphasis in the Iranian context on formal grammar teaching (Rahimpour and Nariman, 2010) as well as Iranian EFL learners' unfamiliarity with planning strategies in the process of writing. Besides, individual differences (Wigglesworth, 1997; Ortega, 2005) may affect the task performance differently. 


\section{Pedagogical Implications}

Most of the studies that have investigated the impact of planning on language production (Crooks, 1989; Ellis, 1987; Ellis and Yuan, 2004; Foster and Skehan, 1996; Mehnert, 1998; Ortega, 1999; Wendel, 1997; and Yuan and Ellis, 2003) suggest that planning is of great value to L2 learners. L2 learners with limited proficiency find it difficult to attend to both meaning and form at the same time therefore they have to make decisions about how to allocate their attentional resources by prioritizing one aspect of language for others (Skehan, 1996; Van Patten, 1990). Skehan (1996) argues that when learners have the opportunity for planning the linguistic and propositional content of a task, they can compensate for these processing limitations, and consequently the quality of their linguistic output is enhanced. So, the findings of the present study make it possible for a teacher or a syllabus designer to design sequences of instructional activities that provide opportunities for the learners to benefit from different types of planning in task performance, as well as various lengths of planning time in order to achieve the goal of balanced development.

Further, planning is considered as one of the main self-regulation processes. Other self-regulation processes include monitoring, evaluating, and revising (Graham \& Harris, 1996). These processes enhance writing effectively resulting in the successful accomplishment of the writing task. Moreover, they lead to strategic adjustments in writing behavior. Thus, the development of writing ability is strongly connected with high-levels of self-regulation that can be taught explicitly. One very effective instructional approach devoted to the development of self-regulatory skills is the self-regulated strategy development (SRSD) approach. It is assumed that it will serve as a remedy to the problems faced by Iranian EFL learners in applying effective writing strategies, particularly planning. Further, findings of this study indicated that Iranian EFL learners are not aware of the effective self-regulatory strategies that are applied by skilled writers. Thus, teaching writing in this context should include explicit instruction on such strategies.

\section{References}

Ahmadian, M. J. (2011). The effects of guided careful online planning on complexity, accuracy, and fluency in intermediate EFL learners' oral production: the case of English articles. Language Teaching Research, 16(1), 1-21.

Crookes, G. (1989). Planning and interlanguage variation. Studies in Second Language Acquisition, 11, 367-383.

Ellis, R. (1987). Interlanguage variability in narrative discourse: Styles shifting in the use of past tense. Studies in Second Language Acquisition, 9, 1-20. http://dx.doi.org/10.1017/ S0272263100006483

Ellis, R. (2005). Planning and task-based performance: theory and research. In Ellis, R. (Ed.), Planning and task performance in a second language. Amsterdam: John Benjamins.

Ellis, R., \& Barkhuizen, G. (2005). Analyzing learner language. Oxford: Oxford University Press.

Ellis, R., \& Yuan, F. (2004). The effects of planning on fluency, complexity, and accuracy in second language narrative writing. Studies in Second Language Acquisition, 26, 59-84. http://dx.doi.org/10.1017/S0272263104261034

Foster, P., \& Skehan, P. (1996). The influence of source of planning and focus of planning on task-based performance. Language Teaching Research, 3(3), 215-247. http://dx.doi.org/10.1177/136216889900300303

Graham S., \& Harris K. R. (1996). Teaching writing strategies within the context of a whole language class. In E. McIntyre \& M. Pressley (Eds.), Skills in whole language. New York: Christopher-Gordon.

Heaton, J. (1975). Beginning composition through pictures. London: Longman.

Kawauchi, C. (2005). The effects of strategic planning on the oral narratives of learners with low and high intermediate proficiency. In R. Ellis (Ed.), Planning and task performance in a second language. pp. 143-164. Amsterdam: John Benjamins.

Malvern, D., \& Richards, B. (2002). Investigating accommodation in language proficiency interviews using a new measure of lexical diversity. Language Testing, 19, 85-104.

Mehnert, U. (1998). The effects of different lengths of time for planning on second language performance. Studies in Second Language Acquisition, 20, 52-83. http://dx.doi.org/10.1017/S0272263198001041

Mochizuki, N., \& Ortega, L. (2008). Balancing communication and grammar in beginning level foreign language classrooms: A study of guided planning and relativization. Language Teaching Research, 12, 11-37. http://dx.doi.org/10.1177/1362168807084492

Ortega, L. (1999). Planning and focus on form in L2 oral performance. Studies in Second Language Acquisition, 21, $108-148$. 
Ortega, L. (2005). What do learners plan? Learner-driven attention to form during pre-task planning. In R. Ellis (Ed.), planning and task performance in a second language (pp. 77 - 111). Amsterdam: John Benjamins.

Rahimpour, M. (2007). Task complexity and variation in L2 learner's oral discourse. Linguistics Working Papers. The University of Queensland, Brisbane, Australia.

Rahimpour, M., \& Nariman, R. (2010). The effects of planning and self-efficacy on EFL learners' written performance. International Journal of Instructional Technology and Distance Learning, 7(9), 19-32.

Rahimpour, M., \& Safarie, M. (2011). The effects of on-line and pre-task planning on descriptive writing of Iranian EFL learners. International Journal of English Linguistics, 1(2), 274-277.

Sangarun. J. (2001). The effects of pre-task planning on foreign language performance. Doctoral thesis. University of Toronto, Canada.

Skehan, P. (1996). A framework for implementation of task-based instruction. Applied Linguistics, 17(1), 38-62. http://dx.doi.org/10.1093/applin/17.1.38

Skehan, P. (1998). A cognitive approach to language learning. Oxford: Oxford University Press.

Skehan, P. (2003). Task-based instruction. Language Teaching, 36(1), 1-14. http://dx.doi.org/10.1017/S026144480200188X

Skehan, P., \& Foster, P. (1997). Task type and task processing conditions as influence on foreign language performance. Language Teaching Research, 1, 185-211.

Skehan, P., \& Foster, P. (1999). The influence of task structure and processing conditions on narrative retellings. Language Learning, 49(1), 93-120. http://dx.doi.org/10.1111/1467-9922.00071

Van Patten, B. (1990). Attending to content and form in the input: an experiment in consciousness. Studies in Second Language Acquisition, 12, 287-301.

Van Patten, B. (1996). Input processing and grammar instruction. New York: Able.

Wendel, J. N. (1997). Planning and second-language narrative production. Doctoral Thesis. Temple University.

Wiggleworth, G. (1997). An investigation of planning time and proficiency level on oral test discourse. Language Testing, 14(1), 85-106. http://dx.doi.org/10.1177/026553229701400105

Yuan, F. (2001). The effects of planning on language production in task-based language teaching. Doctoral thesis, Temple University.

Yuan, F., \& Ellis, R. (2003). The effects of pre-task and on-line planning on fluency, complexity and accuracy in 12 monologic oral production. Applied Linguistics, 24(1), 1-27. http://dx.doi.org/10.1093/applin/24.1.1

Zimmerman, R. (2000). L2 writing: Subprocesses, a model of formulating and empirical findings. Learning and Instruction, 10, 73-99.

Table 1. Task conditions

\begin{tabular}{|l|c|c|c|}
\hline Task condition & Number & Pre-task planning & On-line planning \\
\hline Pre-task planning & 15 & 5 minutes & Limited time \\
\hline Pre-task + On-line Planning & 15 & 5 minutes & Unlimited time \\
\hline On-line planning & 15 & None & Unlimited time \\
\hline
\end{tabular}

Table 2. Descriptive statistics, results of ANOVA, and Scheffé test for fluency

\begin{tabular}{|c|c|c|c|c|c|c|c|c|}
\hline \multirow{2}{*}{$\begin{array}{c}\text { Fluency } \\
\text { variables }\end{array}$} & \multicolumn{3}{|c|}{$\begin{array}{c}\text { M (SD) of } \\
\text { planning conditions }\end{array}$} & \multicolumn{2}{c|}{ ANOVA } & \multicolumn{4}{c|}{$\begin{array}{c}\text { Location of significance: } \\
\text { Scheffé } \mathrm{p}\end{array}$} \\
\cline { 2 - 9 } & PTP & OLP & PTP+OLP & $F$ & $p$ & PTP-OLP & PTP-PTP+OLP & OLP-PTP+OLP \\
\hline Syllables per & 16.03 & 12.96 & 14.69 & 3.34 & .04 & 0.046 & 0.534 & 0.359 \\
Minute & $(2.02)$ & $(3.93)$ & $(3.53)$ & & & & & 0.299 \\
\hline Dysfluencies & 2.29 & 3.41 & 4.72 & 1.24 & .29 & 0.771 & 0.697 \\
& $(2.25)$ & $(5.38)$ & $(4.44)$ & & & & & \\
\hline
\end{tabular}

$* p<.05$. 
Table 3. Descriptive statistics and results of ANOVA for complexity

\begin{tabular}{|c|c|c|c|c|c|}
\hline \multirow{2}{*}{$\begin{array}{c}\text { Complexity } \\
\text { variables }\end{array}$} & \multicolumn{3}{|c|}{$\begin{array}{c}\text { M (SD) of } \\
\text { planning conditions }\end{array}$} & \multicolumn{2}{c|}{ ANOVA } \\
\cline { 2 - 6 } & PTP & OLP & PTP+OLP & $F$ & $p$ \\
\hline Syntactic complexity & 1.53 & 1.63 & 1.62 & .77 & .46 \\
& $(.22)$ & $(.14)$ & $(.32)$ & .14 & .86 \\
\hline Syntactic variety & 34.06 & 33.00 & 35.13 & .04 & .96 \\
& $(8.72)$ & $(10.82)$ & 0.47 & $(0.4)$ & \\
\hline
\end{tabular}

$* p<.05$.

Table 4. Descriptive statistics and results of ANOVA for accuracy

\begin{tabular}{|c|c|c|c|c|c|}
\hline \multirow{2}{*}{$\begin{array}{c}\text { Accuracy } \\
\text { variables }\end{array}$} & \multicolumn{3}{|c|}{$\begin{array}{c}\text { M (SD) of } \\
\text { planning conditions }\end{array}$} & \multicolumn{2}{c|}{ ANOVA } \\
\cline { 2 - 6 } & PTP & OLP & PTP+OLP & $F$ & $p$ \\
\hline Error-free clauses & 83.72 & 82.21 & 85.37 & .20 & .81 \\
& $(9.82)$ & $(19.04)$ & $(9.519)$ & .15 & .85 \\
\hline Correct verbs & 92.39 & 94.10 & 93.70 & $(6.89)$ & \\
\end{tabular}
$* p<.05$.

Table 5. Numbers of participants in each group attending to different aspects of writing task

\begin{tabular}{|c|c|c|c|c|c|c|}
\hline Group & $\begin{array}{c}\text { Picture } \\
\text { comprehension }\end{array}$ & $\begin{array}{c}\text { Rhetorical } \\
\text { planning }\end{array}$ & $\begin{array}{c}\text { Content } \\
\text { planning }\end{array}$ & $\begin{array}{c}\text { Language } \\
\text { planning }\end{array}$ & Use of L1 & Use of note \\
\hline PTP & 15 & 14 & 14 & 7 & 3 & 12 \\
\hline PLP & 15 & 13 & 14 & 13 & 7 & - \\
\hline PTP+OLP & 15 & 14 & 13 & 13 & 8 & 14 \\
\hline
\end{tabular}

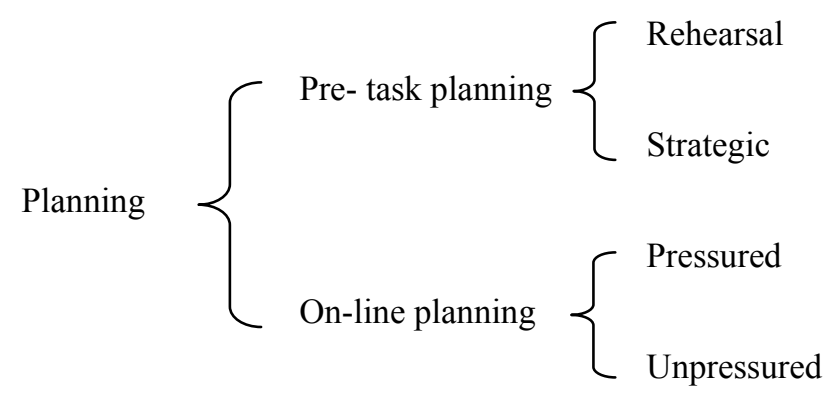

Figure 1. Planning classification in Ellis (2005, p.4) 


\section{Appendix A: Picture adopted from Heaton (1975)}
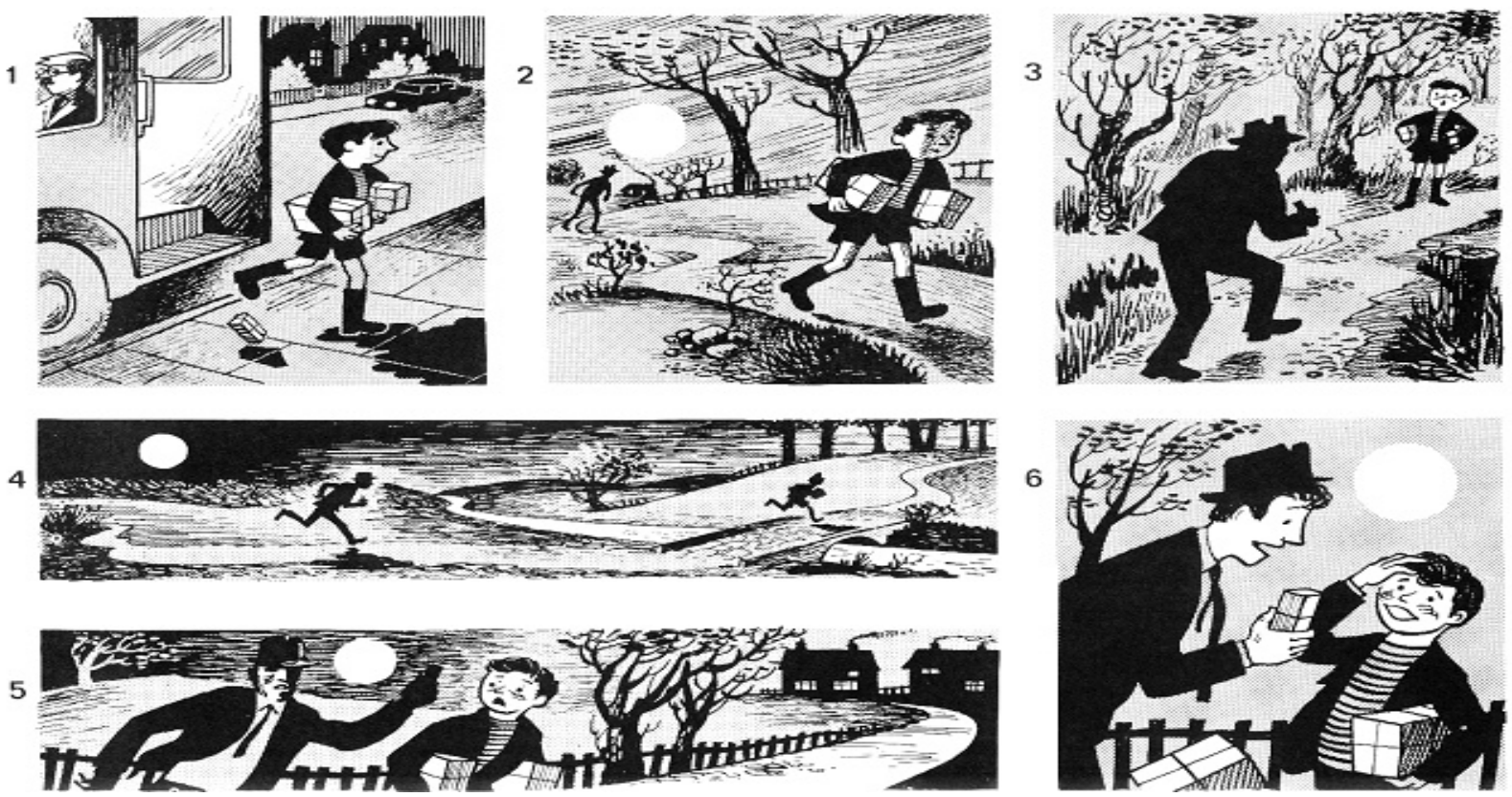

\section{Appendix B: Instructions given to the participants in each group}

\section{Pre-task Planning}

The set of six pictures you have seen tell us a story. Please write a story in English based on the pictures for people who have never seen the pictures and are interested in knowing as much details as possible. Before you begin writing, you will be given five minutes to prepare for your story. You are given a sheet of paper and pencil to help you planning. Use it to write down notes, but please do not write a complete sentence in Persian or English. When you begin writing the story, the sheet of paper will be taken away. During the five minute time, try to think of the vocabulary and grammar you may use and the sequence of the events in the story. You will be given 15 minutes to complete writing the story. In addition, you are required to write at least 200 words during this period of time. Please begin your story with a sentence like "This evening, John......

\section{On-line Planning}

The set of six pictures you have seen tell us a story. Please write a detailed story in English based on the pictures for people who have never seen the pictures and are interested in knowing as much details as possible. While writing the story, try to think of the vocabulary and grammar you may use and the sequence of the events in the story. You can take as long time as you need to complete the story and correct mistakes as many times as necessary. You can also write as many words as you can. Please begin your story with a sentence like "This evening, John........

\section{Pre-task plus On-line Planning}

The set of six pictures you have seen tell us a story. Please write a story in English based on the pictures for people who have never seen the pictures and are interested in knowing as much details as possible. Before you begin writing, you will be given five minutes to prepare for your story. You are given a sheet of paper and pencil to help you planning. Use it to write down notes, but please do not write a complete sentence in Persian or English. When you begin writing the story, the sheet of paper will be taken away. During the five minute time, try to think of the vocabulary and grammar you may use and the sequence of the events in the story. You can take as long time as you need to complete the story and correct mistakes as many times as necessary. You can also write as many words as you can. Please begin your story with a sentence like "This evening, John........ 